\title{
Dermatology Life Quality Index in Patients with Moderate-to-Severe Plaque Psoriasis Treated with Brodalumab or Ustekinumab
}

\author{
Jo Lambert · Jes Birger Hansen · Anne Sohrt · Luis Puig
}

Received: January 29, 2021 / Accepted: April 29, 2021 / Published online: May 14, 2021

(C) The Author(s) 2021

\begin{abstract}
Introduction: Targeted biological therapies for psoriasis have resulted in significant benefits, with therapeutic goals such as clear or almost clear skin accompanied by improvements in health-related quality of life (HRQoL). The objective of this study was to compare the effects of 52 weeks of treatment with brodalumab or ustekinumab on HRQoL in patients with moderate-to-severe plaque psoriasis.

Methods: Data were pooled from two randomised controlled phase 3 trials (AMAGINE-2 and -3) which included patients with moderateto-severe plaque psoriasis treated with brodalumab $210 \mathrm{mg}$ or ustekinumab 45 or $90 \mathrm{mg}$ for 52 weeks. HRQoL outcomes were measured using the Dermatology Life Quality Index (DLQI) as well as the DLQI-Relevant (DLQI-R) version which excludes 'not relevant' responses. Results: A total of 929 patients were included, 339 in the brodalumab group and 590 in the
\end{abstract}

J. Lambert

Department of Dermatology, Ghent University

Hospital, Ghent, Belgium

J. B. Hansen - A. Sohrt

LEO Pharma A/S, Ballerup, Denmark

L. Puig $(\bowtie)$

Department of Dermatology, Hospital de la Santa Creu i Sant Pau-Universitat Autònoma de Barcelona (UAB), Barcelona, Spain

e-mail: LPuig@santpau.cat ustekinumab group. A significantly greater reduction (improvement) in DLQI score from baseline was observed in the brodalumab group compared with the ustekinumab group at weeks 4 [least-squares (LS) mean difference $-2.9,95 \%$ confidence interval $[\mathrm{CI}]-3.6$ to -2.2 ; $p<0.001$ ), 12 (LS mean difference $-0.85,95 \%$ CI -1.5 to $-0.2 ; p=0.01$ ) and 52 (LS mean difference $-0.94, \quad 95 \% \quad C I-1.6$ to -0.2 ; $p=0.009)]$. Significantly greater proportions of patients treated with brodalumab achieved a DLQI score of 0 at weeks 4 (15.0 vs. $5.4 \%$; $p<$ $0.0001), 12$ (37.5 vs. $28.0 \% ; p=0.0140)$ and 52 (46.3 vs. $30.3 \% ; p<0.0001)$, or of $\leq 1$ [DLQI ( $0 /$ 1): 33.9 vs. $15.4 \%, 59.9$ vs. $45.6 \%$ and 54.9 vs. $39.8 \%$, respectively; all $p<0.0001]$. Similar results were observed using the DLQI-R scoring system. Significantly more patients achieved $\mathrm{a} \geq$ 4 or $\geq 5$ improvement in DLQI with brodalumab compared to ustekinumab at weeks 4 and 52. Treatment with brodalumab was associated with significantly more patients achieving a DLQI of 0 compared to ustekinumab for all domains after 4 and 52 weeks.

Conclusion: Brodalumab was associated with a significantly greater improvement in HRQoL compared to ustekinumab in patients with moderate-to-severe psoriasis.

Keywords: Brodalumab; Pharmacology; Psoriasis; Quality of life; Ustekinumab 


\section{Key Summary Points}

Both ustekinumab and brodalumab have been associated with significantly improved health-related quality of life in patients with moderate-to-severe psoriasis, as measured by the Dermatology Life Quality Index (DLQI). Brodalumab has also been shown to provide superior skin clearance to ustekinumab in patients with moderate-to-severe plaque psoriasis in randomised controlled trials.

In an analysis of data pooled from two randomised, controlled, phase 3 trials of patients with moderate-to-severe plaque psoriasis, a significantly greater reduction (improvement) in DLQI score from baseline was observed with brodalumab compared to ustekinumab at weeks 4,12 and 52 .

More patients treated with brodalumab than ustekinumab achieved a DLQI score of 0 or $0 / 1$.

Brodalumab was associated with a significantly greater improvement in HRQoL compared to ustekinumab in patients with moderate-to-severe psoriasis.

\section{DIGITAL FEATURES}

This article is published with digital features, including a summary slide, to facilitate understanding of the article. To view digital features for this article go to https://doi.org/10.6084/ m9.figshare.14501088.

\section{INTRODUCTION}

Psoriasis can have a substantial negative impact on the health-related quality of life (HRQoL) of patients, affecting emotional well-being and interfering with daily activities, including home

life, social activity and work functioning. The use of targeted biological therapies has resulted in significant improvements in the treatment of psoriasis with therapeutic goals, such as clear or almost clear skin, attainable for many patients. These improvements in clinical efficacy have been associated with significant benefits in the self-reported HRQoL of patients [1].

Biological treatments include ustekinumab, which targets the interleukin (IL)-12/23 pathway and, more recently, IL-17 inhibitors, including secukinumab and ixekizumab, which bind to the IL-17 ligand, and brodalumab, which binds to the IL-17 receptor A and inhibits the action of multiple pro-inflammatory IL-17 family cytokines. Both ustekinumab and brodalumab have been associated with significantly improved HRQoL in patients with moderate-to-severe psoriasis, as measured by the Dermatology Life Quality Index (DLQI) [2-5]. Previous studies have suggested that IL-17 inhibition with secukinumab or ixekizumab is associated with greater improvements in skin clearance and HRQoL than ustekinumab [6-8]. Brodalumab has also been shown to provide superior skin clearance to ustekinumab in patients with moderate-to-severe plaque psoriasis in two 1-year randomised controlled trials (AMAGINE-2 and AMAGINE-3) [9]. However, the comparative effects of brodalumab and ustekinumab on HRQoL from these trials have not previously been reported.

Here, we report the effects of 1-year of treatment with brodalumab or ustekinumab on the HRQoL in patients with moderate-to-severe plaque psoriasis enrolled in the AMAGINE-2 and AMAGINE-3 phase 3 trials.

\section{METHODS}

AMAGINE-2 and AMAGINE-3 were two multicentre, randomised, double-blind, placebocontrolled and active comparator-controlled phase 3 trials [9]. In both trials, patients were randomised (2:2:1:1) to brodalumab $210 \mathrm{mg}$ or $140 \mathrm{mg}$, ustekinumab (45 mg for patients with a body weight $\leq 100 \mathrm{~kg}$ and $90 \mathrm{mg}$ for patients $>100 \mathrm{~kg}$ ) or placebo. At week 12, patients originally randomised to brodalumab 
underwent repeat randomisation $(2: 2: 2: 1)$ to brodalumab $210 \mathrm{mg}$ every 2 weeks, $140 \mathrm{mg}$ every 2 weeks, $140 \mathrm{mg}$ every 4 weeks or $140 \mathrm{mg}$ every 8 weeks. Full details of these studies have been previously reported [9]. The present analysis was focused on the on-label dosages for brodalumab so only those patients randomised to brodalumab $210 \mathrm{mg}$ for the entire 52 weeks were included.

Patients eligible for enrolment were aged 18-75 years and candidates for biologic therapy for stable moderate-to-severe plaque psoriasis (minimum disease duration of 6 months) with a psoriasis area and severity index (PASI) score of $\geq 12$, a physician's global assessment (PGA) score of $\geq 3$, and involvement of $\geq 10 \%$ of body surface area. The institutional review board (IRB) at each participating centre approved the study protocols (list of IRBs is given in the Acknowledgements). Both studies were conducted in accordance with the Helsinki Declaration of 1964, and its later amendments and all relevant regional regulations. All patients provided written informed consent.

HRQoL was assessed using the DLQI, a tenitem measure assessing a patient's self-assessment of their quality of life and problems associated with dermatological disease. DLQI total scores range from 0 to 30 , with lower scores indicating better dermatology-specific quality of life and a score of 0 or 1 both representative of no disease effect at all on HRQoL. In the present study, the DLQI questionnaire was completed by patients at baseline and every 4 weeks during the 52-week treatment period. Endpoints included changes in mean DLQI and changes in the six individual domains (symptoms and feelings, daily activities, leisure, work and school, personal relationships and treatment), percentage of patients achieving DLQI total scores of 0 and $\leq 1(0 / 1)$ at weeks 12 and 52 , patients achieving $\mathrm{a} \geq 4$ - or $\geq 5$-point improvement in DLQI from baseline and areaunder-the-curve (AUC) for DLQI 0/1.

Of the ten items of the DLQI, eight include 'not relevant' as a possible response, meaning patients do not consider that the item is applicable to their lifestyle. In the original DLQI, a 'not relevant' response (NRR) is scored as having no impact on the patient's HRQoL. High rates of
NNRs have previously been observed among patients with psoriasis, and concerns have been raised regarding the potential for NRRs to lead to a lower DLQI and thus the patient being categorised as having a higher quality of life than may be the case [10]. An adjusted scoring system for the DLQI that is intended to correct for bias in the NRR option (DLQI-R) has been proposed [11]. The DLQI-R was also used to determine proportions of patients achieving DLQI $0 / 1$ in a post-hoc analysis.

\section{Statistical Analysis}

All binary endpoints were analysed and compared between treatments by odds ratios (ORs) and 95\% confidence intervals (CIs) calculated using a Cochran-Mantel-Haenszel Chi-squared test stratified by total body weight at baseline $(\leq$ or $>100 \mathrm{~kg}$ ), prior biologic use, geographic region and baseline DLQI score $(\leq$ or $>$ median). Missing data for binary endpoints were accounted for by non-responder imputation (NRI).

For continuous outcomes, an analysis of covariance model adjusting for total body weight at week 12 ( $\leq$ or $>100 \mathrm{~kg}$ ), week 12 static PGA (sPGA) response $(0, \geq 1)$, study and treatment was used. Last observation carried forward (LOCF) method was used to impute missing data.

The full analysis set included all patients randomly assigned to treatment with at least one efficacy assessment after randomisation.

All statistical analyses were performed using SAS version 9.4 or higher (SAS Institute Inc., Cary, NC, USA).

\section{RESULTS}

A total of 929 patients were included in the present analysis, 339 in the brodalumab $210 \mathrm{mg}$ group and 590 in the ustekinumab group. Baseline demographic and clinical characteristics were similar across both groups (Table 1). DLQI at baseline was similar in both treatment groups, with mean $[ \pm$ standard deviation $(\mathrm{SD})]$ scores of $14.8 \pm 7.3$ in the brodalumab group and $14.9 \pm 7.3$ in the ustekinumab group. 
Table 1 Baseline characteristics of patients

\begin{tabular}{|c|c|c|}
\hline Baseline characteristic & $\begin{array}{l}\text { Brodalumab } \\
(n=339)\end{array}$ & $\begin{array}{l}\text { Ustekinumab } \\
(n=590)\end{array}$ \\
\hline Age, years & $44.5(13.4)$ & $45.1(13.0)$ \\
\hline Male, $n(\%)$ & $230(67.8)$ & $404(68.5)$ \\
\hline Weight, kg & $90.4(24.2)$ & $91.0(22.9)$ \\
\hline Race, white, $n$ (\%) & $308(90.9)$ & $532(90.2)$ \\
\hline Disease duration, years & $17.3(11.7)$ & $18.6(12.2)$ \\
\hline $\begin{array}{r}\text { Body surface area } \\
\text { involvement, } \%\end{array}$ & $27.0(16.2)$ & $27.6(18.6)$ \\
\hline $\begin{array}{l}\text { Psoriasis area and } \\
\text { severity index (PASI) } \\
\text { score }\end{array}$ & $20.4(7.9)$ & $20.0(8.4)$ \\
\hline $\begin{array}{l}\text { Dermatology Life } \\
\text { Quality Index (DLQI) } \\
\text { score }\end{array}$ & $14.8(7.3)$ & $14.9(7.3)$ \\
\hline $\begin{array}{l}\text { Nail Psoriasis Severity } \\
\text { Index (NAPSI) score }\end{array}$ & $9.3(3.6)$ & $9.9(3.6)$ \\
\hline $\begin{array}{l}\text { Psoriasis Symptom } \\
\text { Inventory (PSI) score }\end{array}$ & $19.1(7.0)$ & $18.7(6.9)$ \\
\hline Psoriatic arthritis, $n(\%)$ & $79(23.3)$ & $110(18.6)$ \\
\hline $\begin{array}{l}\text { Systemic treatment- } \\
\text { naïve, } n(\%)\end{array}$ & $144(42.5)$ & $246(41.7)$ \\
\hline $\begin{array}{l}\text { Previous non-biologic } \\
\text { systemic treatment, } \\
n(\%)\end{array}$ & $99(29.2)$ & $188(31.9)$ \\
\hline $\begin{array}{l}\text { Previous biologic } \\
\text { without failure, } n(\%)\end{array}$ & $50(14.8)$ & $95(16.1)$ \\
\hline $\begin{array}{l}\text { Previous biologic failure, } \\
n(\%)\end{array}$ & $46(13.6)$ & $61(10.3)$ \\
\hline
\end{tabular}

All data are presented as the mean with the standard deviation $(\mathrm{SD})$ in parentheses unless otherwise indicated

Mean individual domain scores were also similar between groups at baseline.

A significantly greater reduction (improvement) in DLQI score from baseline was observed in the brodalumab group compared with the ustekinumab group at weeks 4 [mean $\pm \mathrm{SD}-$
Fig. 1 Proportions of patients achieving DLQI score of 0 (a) or $0 / 1$ (b) or a DLQI-R score of $0 / 1$ (c) per visit with brodalumab or ustekinumab (full analysis set, non-responder imputation). DLQI Dermatology Life Quality Index, $D L Q I-R$ adjusted DLQI correcting for bias in the 'not relevant' response (NRR), Q2W once every 2 weeks

$10.4 \pm 7.0$ vs. $-7.5 \pm 6.3$; least-squares (LS) mean difference $-2.9,95 \% \mathrm{CI}-3.6$ to -2.2 ; $p<0.001], \quad 12$ [- $11.7 \pm 7.8$ vs. $-10.9 \pm 7.2$; LS mean difference $-0.85,95 \% \mathrm{CI}-1.5$ to $-0.2 ; p=0.01]$ and $52[-12.1 \pm 8.1$ vs. $11.2 \pm 7.7$; LS mean difference $-0.94,95 \%$ CI -1.6 to $-0.2 ; p=0.009$ ].

Significantly greater proportions of patients treated with brodalumab achieved a DLQI score of 0 at week 4 compared with ustekinumabtreated patients ( 15.0 vs. $5.4 \%$; OR $2.95,95 \%$ CI $1.82-4.79 ; \quad p<0.0001)$ and this difference remained significant at weeks 12 (37.5 vs. 28.0\%; OR 1.45, 95\% CI 1.08-1.95; $p=0.0140$ ) and 52 (46.3 vs. 30.3\%; OR 2.08, 95\% CI 1.55-2.78; $p<0.0001]$ ) (Fig. 1a). Similarly, among patients with a DLQI score $>1$ at baseline, more patients in the brodalumab group than ustekinumab group achieved a DLQI score of $0 / 1$ at weeks 4 (33.9 vs. $15.4 \%$; OR $2.82,95 \%$ CI 2.01-3.95; $p<0.0001$ ), 12 (59.9 vs. $45.6 \%$; OR 1.74, 95\% CI 1.32-2.31; $p<0.0001)$ and 52 (54.9\% vs. $39.8 \%$; OR $1.90,95 \%$ CI $1.43-2.53$; $p<0.0001$ ) (Fig. 1b). The AUC for patients achieving DLQI 0/1 was significantly higher for those receiving brodalumab than for those on ustekinumab (53.1 vs. $39.7 \%$; AUC ratio 1.34; $p<0.0001$ ) (Fig. 2).

An analysis using the adjusted DLQI-R scoring system showed generally similar results for the proportions of patients achieving DLQI-R $0 / 1$, although there was a slightly lower proportion of patients achieving DLQI-R 0/1 compared to DLQI 0/1 (Fig. 1c). NRRs were most frequent for the sport $(13.5 \%)$, working/studying (11.6\%) and sexual difficulties (10.1\%) items, with other items having 1.2-3.6\% NRRs. As with the unadjusted DLQI, a significantly higher proportion of patients achieved DLQI-R $0 / 1$ with brodalumab than ustekinumab at weeks 4 (30.1 vs. 12.2\%; OR 3.00, 95\% CI $2.10-4.29 ; p<0.0001), 12$ (55.5 vs. $41.4 \%$; OR 


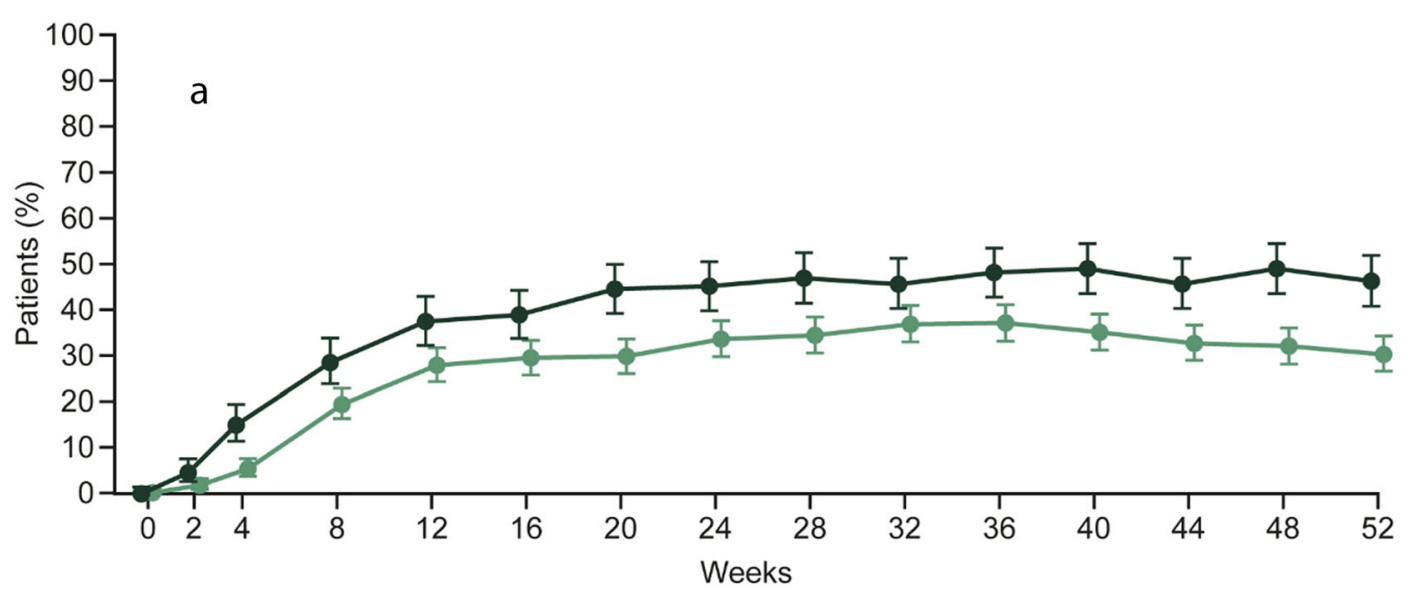

Treatment: — Brodalumab $210 \mathrm{mg} \mathrm{Q2W} \mathrm{—} \mathrm{Ustekinumab} 45$ or $90 \mathrm{mg}$

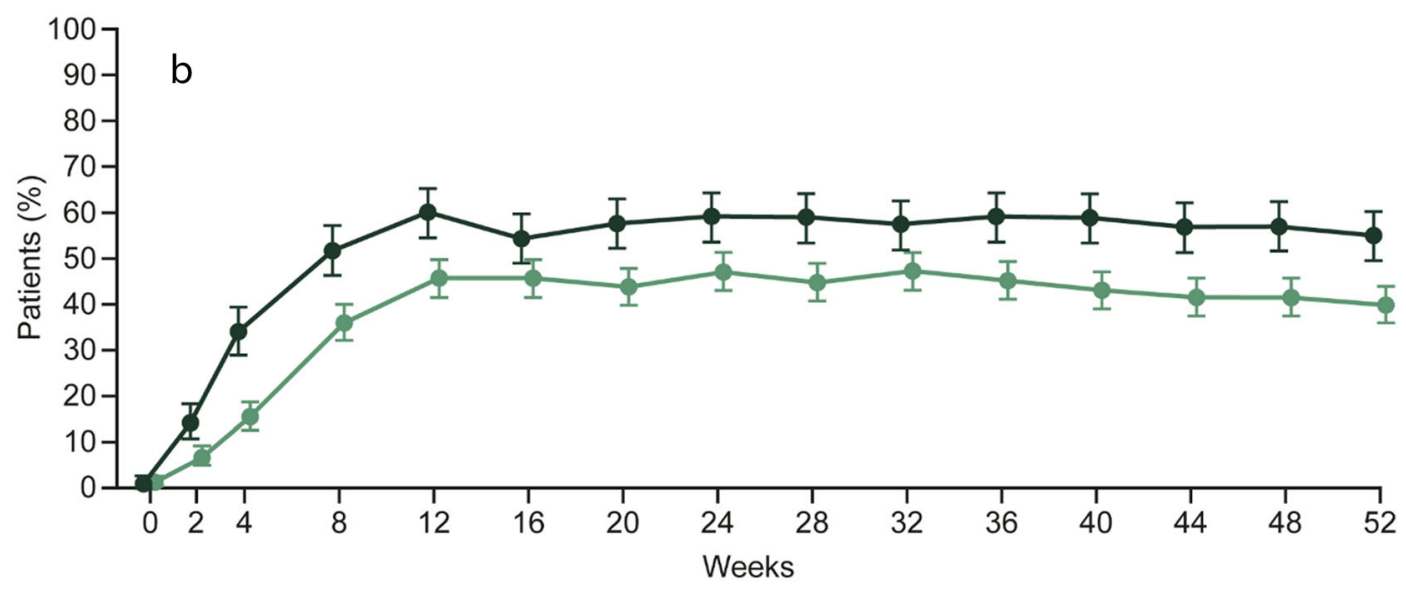

Treatment: — Brodalumab $210 \mathrm{mg} \mathrm{Q2W} \mathrm{—Ustekinumab} 45$ or $90 \mathrm{mg}$

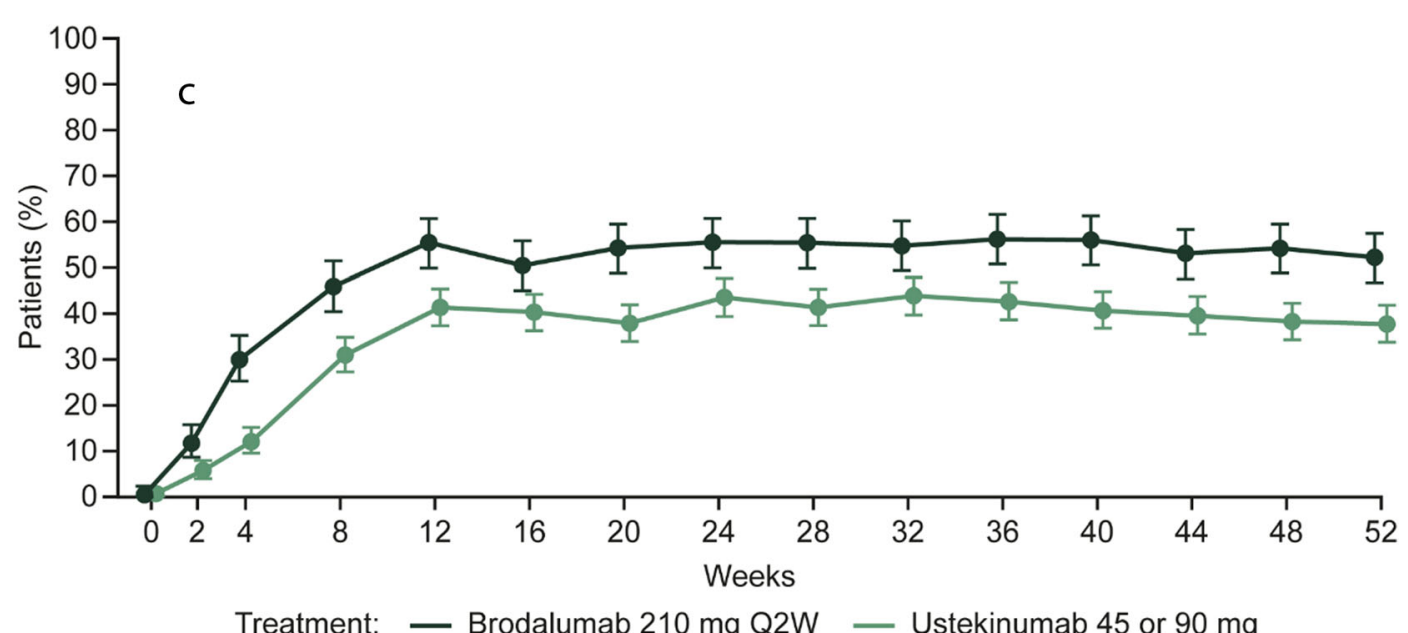

Treatment: — Brodalumab 210 mg Q2W — Ustekinumab 45 or 90 mg 


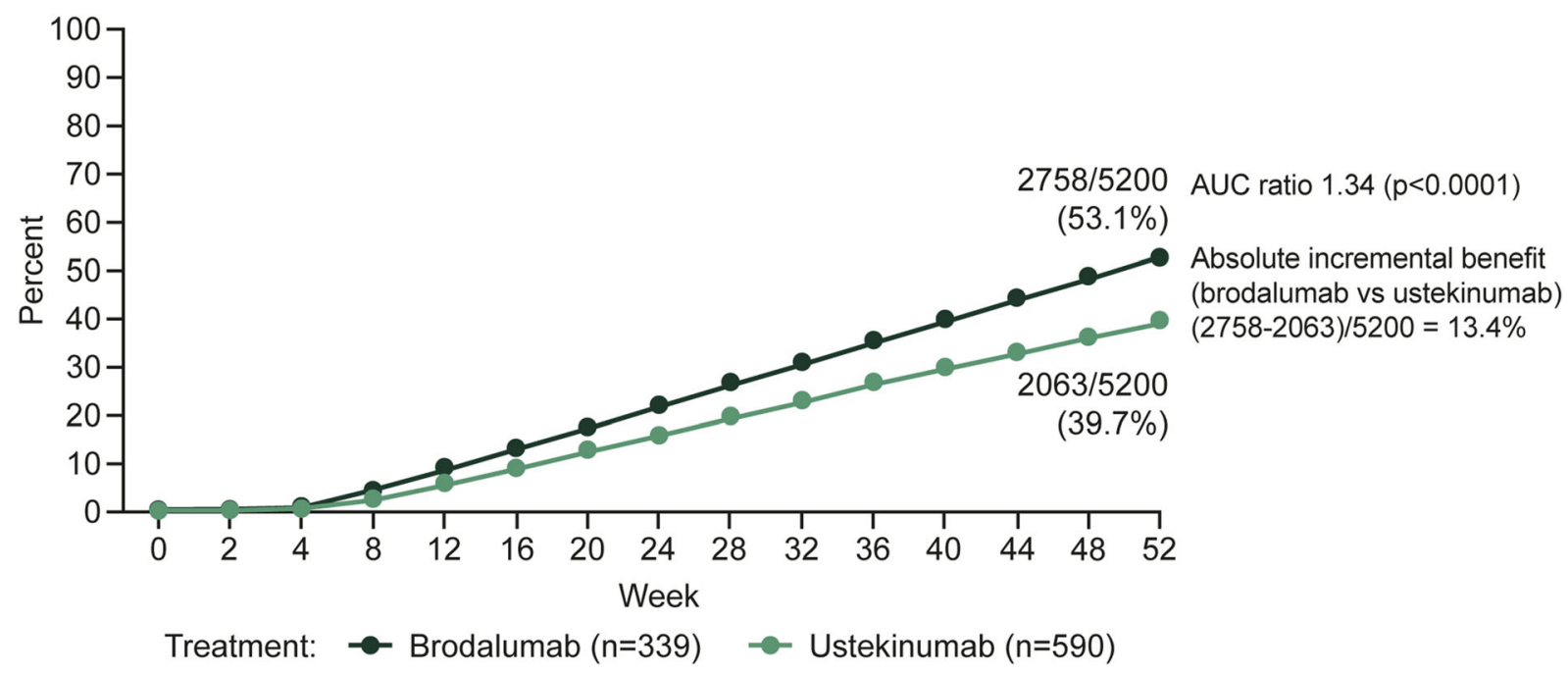

Fig. 2 The AUC for DLQI score 0/1 with brodalumab or ustekinumab. AUC $=100 \%$ would mean $100 \%$ of patients achieve and maintain DLQI 0/1 from week 0 to week 52 (ideal response). AUC Area-under-the-curve

$1.75,95 \%$ CI $1.32-2.32 ; p<0.0001)$ and 52 (52.2 vs. $37.8 \%$; OR 1.88 , 95\% CI $1.41-2.50$; $p<0.0001)$.

Among patients with baseline DLQI $\geq 4$, significantly more achieved $a \geq 4$-point improvement with brodalumab compared with ustekinumab at week 4 and week 52, although not at week 12 (Fig. 3). A similar pattern was seen among patients with baseline DLQI $\geq 5$ at weeks 4 (83.6 vs. 67.7\%; OR 2.73, 95\% CI $1.87-3.99 ; p<0.0001), 12$ (88.2 vs. $86.4 \%$; OR $1.24,95 \%$ CI $0.80-1.92 ; p=0.3384)$ and 52 (62.8 vs. $48.5 \%$; OR $1.88,95 \%$ CI $1.40-2.54$; $p<0.0001)$.

Treatment with brodalumab was associated with significantly more patients achieving DLQI 0 compared to ustekinumab for the domains of symptoms and feelings, daily activities, leisure

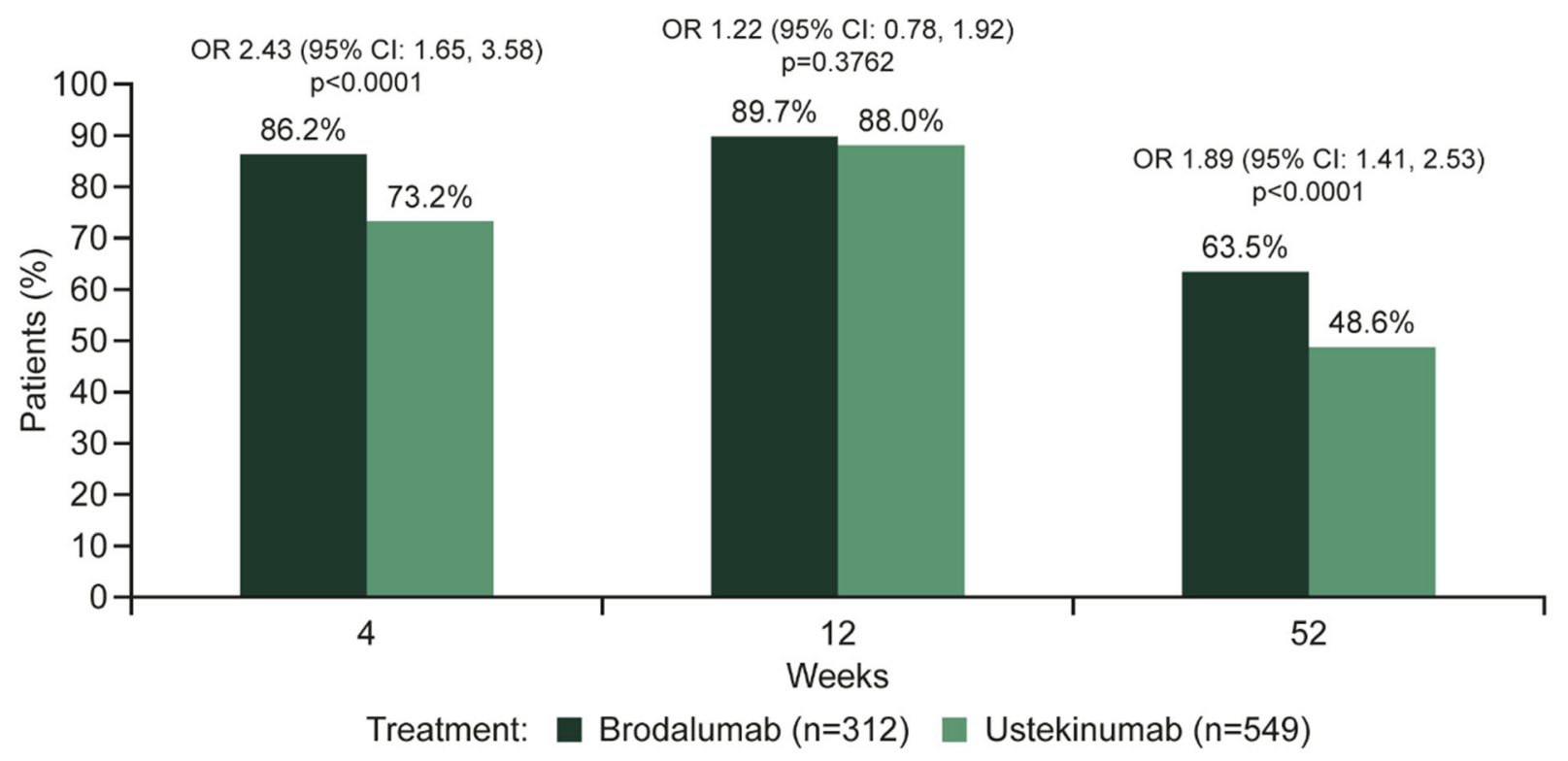

Fig. 3 Patients achieving an improvement in DLQI of $\geq 4$ points with brodalumab and ustekinumab at 4, 12 and 52 weeks (full analysis set, non-responder imputation). $C I$ Confidence interval, $O R$ odds ratio 

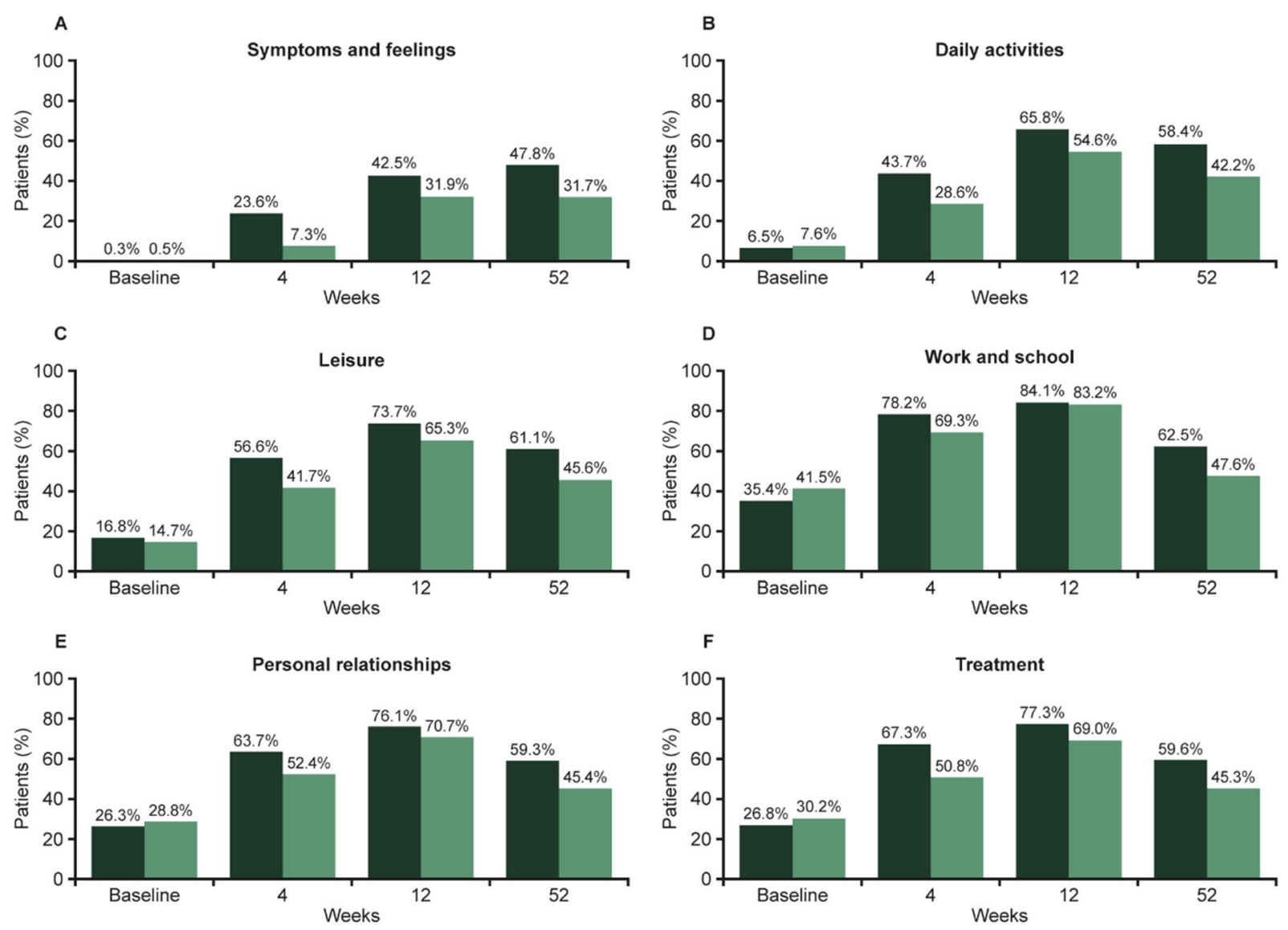

Treatment: - Brodalumab $(\mathrm{n}=312)$ = Ustekinumab $(\mathrm{n}=549)$

Fig. 4 Patients achieving DLQI 0 for individual domains with brodalumab and ustekinumab at 4, 12 and 52 weeks (full analysis set, non-responder imputation)

and treatment after 4, 12 and 52 weeks (Fig. 4). Proportions of patients achieving DLQI 0 were also significantly higher with brodalumab versus ustekinumab for work and school and personal relationships at weeks 4 and 52 but were not significantly different between groups at week 12 .

\section{DISCUSSION}

Psoriasis represents a considerable burden for patients, often resulting in feelings of embarrassment and anxiety and poor self-esteem and limiting daily, social and work-related activities $[12,13]$. Biological treatments such as brodalumab and ustekinumab have resulted in significant improvements in outcomes for patients with moderate-to-severe psoriasis, with complete or near complete skin clearance now a realistic treatment goal. However, patients with psoriasis and their physicians may differ regarding how much importance they place on different treatment outcomes [14]. To be clinically meaningful for patients, objective improvements in symptoms, such as those reported by PASI, need to be accompanied by improvements in subjective self-reported HRQoL measures, including the DLQI.

Several studies have previously reported that both brodalumab and ustekinumab improve HRQoL. In a phase II, randomised, placebocontrolled clinical study of 198 patients with moderate-to-severe psoriasis, clinically meaningful improvements in DLQI were observed as early as week 4 following initiation of treatment 
with brodalumab [4]. DLQI scores were significantly improved across all domains at week 12 . In a 5-year open-label extension of this study, treatment with brodalumab resulted in substantial improvements in HRQoL, with over two-thirds of patients achieving DLQI 0/1 from week 12 through to week 264 [15]. Ustekinumab has also been associated with significant improvements in HRQoL as measured by the DLQI $[2,3]$, which have been reported to be maintained for up to 3 years of treatment [16]. Ustekinumab was also associated with a sustained improvement in DLQI among 489 patients with psoriasis after transitioning from methotrexate [17]. However, DLQI improvements with ustekinumab have been reported to be less than those with the IL-17 inhibitors secukinumab or ixekizumab $[7,8]$.

In the present study, improvements in HRQoL were significantly greater with brodalumab than with ustekinumab. Also, mean DLQI scores were lower, and more patients achieved a DLQI of 0 or $0 / 1$ with brodalumab at weeks 4, 12 and 52, indicating a more rapid improvement in HRQoL with the difference being maintained over 1 year of treatment. More patients also achieved $\mathrm{a} \geq 4$-point improvement with brodalumab compared with ustekinumab, which is the recommended minimal clinically important difference of the DLQI [18]. The cumulative benefit of brodalumab over ustekinumab regarding HRQoL was confirmed by the AUC ratio for DLQI 0/1 of 1.34 . Improvements were also seen in each individual DLQI domain.

Improvement in quality of life tends to be associated with high skin clearance scores [15]. PASI and DLQI are closely correlated, with a substantial improvement in clinical efficacy associated with improved HRQoL in patients with moderate-to-severe psoriasis, and a significant difference in DLQI score of $0 / 1$ between PASI 75 and PASI $<90$ responders $(\geq 75 \%$ and $<90 \%$ reduction in PASI scores from baseline, excellent to even better disease improvement, respectively) and PASI 90 responders [1]. In a separate analysis of the AMAGINE-2 and -3 trials, a significant association was observed between the PASI response level and achievement of DLQI $0 / 1$, regardless of treatment arm.
More patients who achieved PASI 100 (complete resolution of all disease) than PASI 90 to $<100$ also achieved DLQI 0/1 (83.5 vs. 64.3\%) [19]. In the previous phase II trial of brodalumab, patients who achieved total skin clearance (PASI 100) reported greater HRQoL improvements than those who were responders but were not clear of disease (PASI 75 to $<100$ ) [20]. In addition, more patients achieved a DLQI score of 0 in the PASI 90 to $<100$ and PASI 100 groups compared with the PASI 75 to $<90$ group [21]. However, Abrouk et al. reported no significant differences in DLQI between patients achieving PASI 75 or PASI 90 in an analysis of two ustekinumab clinical trials [22]. In a realworld setting, improvements in PASI were observed to be only weakly to moderately associated with improvements in DLQI in patients treated with ustekinumab [23]. Similarly, data from the Danish National Registry also suggested that the correlation between PASI and DLQI is weak to moderate and varies over time [24]. More research is needed to confirm the correlation between PASI and DLQI outcomes, especially outside of clinical trials.

Of the ten questions of the DLQI, eight offer an NRR option that is scored as if the item had no impact on patients, as a value of 0 is counted for an NRR response. This can mean it is more difficult for these patients to fulfil the DLQI > 10 criterion required to access biologic treatment in some clinical guidelines. Female gender, older age and more severe disease have previously been associated with more NRRs [10]. To address this, a new scoring formula (DLQI-R) that adjusts the total score for the number of NRRs has been proposed [11]. In our analysis, the use of DLQI-R did not have a major effect on the proportions of patients achieving DLQI 0/1. For both treatments, the proportions of patients achieving DLQI 0/1 was slightly lower using DLQI-R than DLQI, which is the opposite effect to that previously reported [10]. Most NRRs occurred in the sport, sexual difficulties and working/studying items of the DLQI, which is consistent with previous findings. However, the proportions of reported NRRs were lower in our analysis than previously reported; for example, the domain with the highest proportion of NRRs, sport, had 13.5\% 
NNRs compared with $28.4 \%$ reported by Rencz et al. [10]. The model was originally developed based on data collected in cross-sectional analyses and it is possible that patients enrolled in clinical trials may be less likely to include 'not relevant' as a response. If this is the case, the use of DLQI-R may be less useful in a clinical trial setting than when used to help guide treatment decisions in clinical practice. Further validation in clinical trials and clinical practice is required.

One possible limitation of this analysis is that the original AMAGINE-2 and -3 studies were conducted between 2012 and 2014 . Advances in treatment and greater disease awareness among patients in the ensuing years may have resulted in increased expectations of complete skin clearance and improvements in HRQoL. This may need to be taken into consideration if comparing these DLQI results with those of more recent studies. However, this would not have impacted on the comparative aspect of this trial.

In conclusion, brodalumab treatment provided significant improvement in self-reported HRQoL in patients with moderate-to-severe psoriasis compared with ustekinumab.

\section{ACKNOWLEDGEMENTS}

Funding. This analysis and manuscript development, including Rapid Service Fee, was funded by Leo Pharma A/S.

Authorship. All named authors meet the International Committee of Medical Journal Editors (ICMJE) criteria for authorship for this article, take responsibility for the integrity of the work as a whole, and have given their approval for this version to be published.

Medical Writing and Editorial Assistance. Medical writing and editorial assistance were provided by Andy Bond of Spirit Medical Communications Group Ltd., funded by Leo Pharma A/S.

Disclosures. Anne Sohrt and Jes Birger Hansen are employees of Leo Pharma A/S. Jo
Lambert has received consultancy/speaker's honoraria from and/or participated in clinical trials sponsored by Abbvie, Almirall, Amgen, ArgenX, Celgene, Janssen, BIOCAD, LEO Pharma, Lilly, Novartis, Pfizer, Sanofi, and UCB. Lluís Puig has received consultancy/speaker's honoraria from and/or participated in clinical trials sponsored by Abbvie, Almirall, Amgen, Baxalta, Biogen, Boehringer Ingelheim, Celgene, Gebro, Janssen, JS BIOCAD, LEO Pharma, Lilly, Merck-Serono, MSD, Mylan, Novartis, Pfizer, Regeneron, Roche, Sandoz, SamsungBioepis, Sanofi, and UCB.

Compliance with Ethics Guidelines. An institutional review board approved the study protocol for each participating center. These were: Research Review Board, Inc. Richmond Hill, ON, Canada; Health Research Ethics Board of Alberta Clinical Trials Committee, Edmonton, AB, Canada; Eticka Komise Fakultni nemocnice Kralovske Vinohrady, Praha, Czech Republic; Eticka Komise Fakultni nemocnice Kralovske Vinohrady, Brno, Czech Republic; Eticka Komise Fakultni nemocnice, Praha Czech Republic; Eticka Komise Fakultni nemocnice Kralovske Vinohrady, Usti nad Labem, Czech Republic; Eticka Komise Fakultni nemocnice, Novy Jicin, Czech Republic; Eticka Komise Fakultni nemocnice, Jihlava, Czech Republic; Comité de Protection des Personnes Ile de France IV - Hôpital Saint Louis, Paris, France; Egeszsegugyi Tudomanyos Tanacs, Klinikai Farmakologiai Etikai Bizottsaga, Budapest, Hungary; Academisch Medisch Centrum, Amsterdam, the Netherlands; Komisja Bioetyczna przy Okregowej Izbie Lekarskiej w Lodzi, Lodz, Poland; Comissao de Etica para a Investigacao Clinica (CEIC), Lisboa, Portugal; CEIC Fundacio de Gestio Sanitaria Hospital de la Santa Creu i Sant Pau, Barcelona, Spain; University of California Davis Institutional Review Board, Sacramento, CA, USA; Schulman Associates IRB, Cincinnati, OH, USA; Oregon Health and Science University Research Integrity Office,Portland, OR, USA; Western Institutional Review Board, Puyallup, WA, USA; Northwestern University IRB, Chicago, IL, USA; University of Michigan Medical School IRB, Ann Arbor, MI, USA; Partners Human Research 
Committee/Partners Human Research Office, Boston, MA, USA; NorthShore University HealthSystem IRB, Evanston, IL, USA; Duke University Health System IRB, Durham, NC, USA; University of California Irvine Office of Research IRB, Irvine, CA, USA; Kaiser Permanente Southern California IRB, Pasadena, CA, USA; New York Harbor Health Care System Subcommittee for Human Studies, New York, NY, USA; Tulane University Human Research Protection Office, New Orleans, LA, USA; Ethikkommission Nordwest- und Zentralschweiz (EKNZ), Basel, Switzerland; Commission cantonale d'éthique de la recherche sur l'être humain, Lausanne, Switzerland; Kantonale Ethikkommission, Zürich, Switzerland; Ethikkommission des Fachbereichs Medizin, Frankfurt am Main, Germany; Probity Medical Research Corporation, Waterloo, ON, Canada; Washington University School of Medicine, Human Research Protection Office, St. Louis, MO, USA; Comite de Protection des Personnes Sud Ouest et Outre Mer I et II, Toulouse, France; Commission centrale d'ethique des Hopitaux Universitaires de Geneve, Geneva, Switzerland; Komisja Bioetyczna przy Okregowej Izbie Lekarskiej, Krakow, Poland; Comite de Protection des Personnes Sud Est II Hopital Edouard Herriot, Lyon, France; Creighton University IRB, Omaha, NE, USA; University of California at San Francisco, Committee of Human Research, San Francisco, CA, USA; University of California at San Diego, Human Research Protections Program, La Jolla, CA, USA; Medicor Research Inc, Sudbury, ON, Canada; Capital District Health Authority Research Ethics Board, Halifax, NS, Canada; University Hospitals of Cleveland IRB, Cleveland, OH, USA; Kantonale Ethikkommission Bern, Bern, Switzerland. Both studies were performed in accordance with the Helsinki Declaration of 1964, and its later amendments. All subjects provided informed consent to participate in the study.

Data Availability. The datasets generated during and/or analysed during the current study are available from the corresponding author on reasonable request.
Open Access. This article is licensed under a Creative Commons Attribution-NonCommercial 4.0 International License, which permits any non-commercial use, sharing, adaptation, distribution and reproduction in any medium or format, as long as you give appropriate credit to the original author(s) and the source, provide a link to the Creative Commons licence, and indicate if changes were made. The images or other third party material in this article are included in the article's Creative Commons licence, unless indicated otherwise in a credit line to the material. If material is not included in the article's Creative Commons licence and your intended use is not permitted by statutory regulation or exceeds the permitted use, you will need to obtain permission directly from the copyright holder. To view a copy of this licence, visit http://creativecommons.org/licenses/by$\mathrm{nc} / 4.0 /$.

\section{REFERENCES}

1. Puig L, Thom H, Mollon P, et al. Clear or almost clear skin improves the quality of life in patients with moderate-to-severe psoriasis: a systematic review and meta-analysis. J Eur Acad Dermatol Venereol. 2017;31(2):213-20.

2. Lebwohl M, Papp K, Han C, et al. Ustekinumab improves health-related quality of life in patients with moderate-to-severe psoriasis: results from the PHOENIX 1 trial. Br J Dermatol. 2010;162(1): 137-46.

3. Langley RG, Feldman SR, Han C, et al. Ustekinumab significantly improves symptoms of anxiety, depression, and skin-related quality of life in patients with moderate-to-severe psoriasis: results from a randomized, double-blind, placebo-controlled phase III trial. J Am Acad Dermatol. 2010;63(3):457-65.

4. Gordon KB, Kimball AB, Chau D, et al. Impact of brodalumab treatment on psoriasis symptoms and health-related quality of life: use of a novel patientreported outcome measure the Psoriasis Symptom Inventory. Br J Dermatol. 2014;170(3):705-15.

5. Papp KA, Gordon KB, Langley RG, et al. Impact of previous biologic use on the efficacy and safety of brodalumab and ustekinumab in patients with moderate-to-severe plaque psoriasis: integrated analysis of the randomized controlled trials 
AMAGINE-2 and AMAGINE-3. Br J Dermatol. 2018;179:320-8.

6. Blauvelt A, Reich K, Tsai TF, et al. Secukinumab is superior to ustekinumab in clearing skin of subjects with moderate-to-severe plaque psoriasis up to 1 year: Results from the CLEAR study. J Am Acad Dermatol. 2017;76(1):60-69.e9.

7. Reich K, Pinter A, Lacour JP, et al. Comparison of ixekizumab with ustekinumab in moderate-to-severe psoriasis: 24-week results from IXORA-S, a phase III study. Br J Dermatol. 2017;177(4):1014-23.

8. Puig L, Augustin M, Blauvelt A, et al. Effect of secukinumab on quality of life and psoriasis-related symptoms: a comparative analysis versus ustekinumab from the CLEAR 52-week study. J Am Acad Dermatol. 2018;78(4):741-8.

9. Lebwohl M, Strober B, Menter A, et al. Phase 3 studies comparing brodalumab with ustekinumab in psoriasis. N Engl J Med. 2015;373(14):1318-28.

10. Rencz F, Poór AK, Péntek M, et al. A detailed analysis of "not relevant" responses on the DLQI in psoriasis: potential biases in treatment decisions. J Eur Acad Dermatol Venereol. 2018;32(5):783-90.

11. Rencz F, Gulácsi L, Péntek M, et al. Proposal of a new scoring formula for the Dermatology Life Quality Index in psoriasis. $\mathrm{Br} \mathrm{J}$ Dermatol. 2018;179(5):1102-8.

12. Kimball AB, Jacobson $C$, Weiss $S$, et al. The psychosocial burden of psoriasis. Am J Clin Dermatol. 2005;6(6):383-92.

13. Augustin M, Radtke MA. Quality of life in psoriasis patients. Expert Rev Pharmacoecon Outcomes Res. 2014;14(4):559-68.

14. Strober BE, van der Walt JM, Armstrong AW, et al. Clinical goals and barriers to effective psoriasis care. Dermatol Ther (Heidelb). 2019;9:5-18.

15. Lebwohl MG, Blauvelt A, Menter A, et al. Efficacy, safety, and patient-reported outcomes in patients with moderate-to-severe plaque psoriasis treated with brodalumab for 5 years in a long-term, openlabel, phase II study. Am J Clin Dermatol. 2019;20(6):863-71.
16. Kimball AB, Gordon $\mathrm{KB}$, Fakharzadeh $\mathrm{S}$, et al. Longterm efficacy of ustekinumab in patients with moderate-to-severe psoriasis: results from the PHOENIX 1 trial through up to 3 years. Br J Dermatol. 2012;166(4):861-72.

17. Augustin M, Blome C, Paul C, et al. Quality of life and patient benefit following transition from methotrexate to ustekinumab in psoriasis. J Eur Acad Dermatol Venereol. 2017;31(2):294-303.

18. Basra MK, Salek MS, Camilleri L, et al. Determining the minimal clinically important difference and responsiveness of the Dermatology Life Quality Index (DLQI): further data. Dermatology. 2015;230: 27-33.

19. Warren RB, Hansen JB, Reich K, et al. Complete clearance and psoriasis area and severity index response for brodalumab and ustekinumab in AMAGINE-2 and -3. J Eur Acad Dermatol Venereol. 2020. https://doi.org/10.1111/jdv.16816.10.1111/ jdv.16816.

20. Viswanathan HN, Chau D, Milmont CE, et al. Total skin clearance results in improvements in healthrelated quality of life and reduced symptom severity among patients with moderate to severe psoriasis. J Dermatolog Treat. 2015;26(3):235-9.

21. Revicki DA, Jin Y, Wilson HD, et al. Reliability and validity of the psoriasis symptom inventory in patients with moderate-to-severe psoriasis. J Dermatolog Treat. 2014;25(1):8-14.

22. Abrouk M, Nakamura M, Zhu TH, et al. The impact of PASI 75 and PASI 90 on quality of life in moderate to severe psoriasis patients. J Dermatolog Treat. 2017;28(6):488-91.

23. Hesselvig JH, Egeberg A, Loft ND, et al. Correlation between dermatology life quality index and psoriasis area and severity index in patients with psoriasis treated with ustekinumab. Acta Derm Venereol. 2018;98(3):335-9.

24. Loft ND, Egeberg A, Rasmussen MK, et al. Patientreported outcomes during treatment in patients with moderate-to-severe psoriasis: a Danish nationwide study. Acta Derm Venereol. 2019;99(13):1224-30. 